\title{
Potencialidades do agir crítico em Nutrição na Atenção Primária à Saúde a partir da perspectiva da educação popular: algumas reflexões
}

Pedro José Santos Carneiro Cruz¹

\section{Resumo}

As experiências de agir crítico em Nutrição Social vêm configurando contraponto prático e epistemológico para as ações de educação alimentar e nutricional que se pautam pelo tecnicismo e pela transmissão vertical de informações com foco no conhecimento do especialista. Este ensaio constitui exercício reflexivo sobre esse agir, tendo como horizonte práticas na Atenção Primária à Saúde (APS). Contextualizamos historicamente esse agir e apontamos as vivências cotidianas na realidade social como caminho na Nutrição em APS. Problematizamos que esse agir pressupõe, dentre suas dimensões, engajamento e compromisso com a realidade social, tendo como referencial tanto a construção de vínculos e diálogos interculturais, como o enfrentamento ao capitalismo. Esse agir perpassa uma abordagem multifacetada da ciência da Nutrição, compreendendo a alimentação como prática social, cultural e plena de sentidos nas vidas das pessoas e das coletividades.

\section{Palavras-chave}

Nutrição. Educação Popular. Atenção Primária à Saúde. Educação Alimentar e Nutricional. Educação em Saúde.

1. Doutor em Educação pela Universidade Federal da Paraíba, Brasil; professor adjunto do Departamento de Promoção da Saúde do Centro de Ciências Médicas e professor permanente do Programa de Pós-Graduação em Educação do Centro de Educação da Universidade Federal da Paraíba, Brasil. E-mail: pjcruzpb@gmail.com. 


\title{
Potentialities of critical action in Nutrition in Primary Health Care from the perspective of popular education:
} some reflections

Pedro José Santos Carneiro Cruz ${ }^{1 *}$

\begin{abstract}
The experiences of critical action in Social Nutrition have been forming a practical and epistemological counterpoint for actions of food and nutritional education that are based on technicalism and vertical transmission of information focused on the expert's knowledge. This essay is a reflective exercise on this action, having as a horizon practices in Primary Health Care (PHC). We contextualize the history of that action and point out the daily experiences in social reality as a path of Nutrition in $\mathrm{PHC}$. We problematize that this action assumes, among its dimensions, commitment and engaging to social reality, having as reference both the construction of intercultural ties and dialogues, as well as the confrontation with capitalism. This action permeates a multifaceted approach to the science of nutrition, understanding food as a social, cultural and sensorial practice in the lives of people and communities.
\end{abstract}

\section{Keywords}

Nutrition. Popular Education. Primary Health Care. Food and Nutrition Education. Education in Health.

\footnotetext{
* PhD in Education, Federal University of Paraíba, State of Paraíba, Brazil; assistant professor of the Department of Health Promotion / Center of Medical Sciences and permanent professor of the Program of Post-Graduation in Education / Education Center in the same institution. E-mail: pjcruzpb@gmail.com.
} 


\section{Introdução}

O movimento de reorientação da ciência da Nutrição e sua prática profissional tem crescido. Ele é impulsionado por fatores de interesse social e científico, dentre eles: a persistência do fenômeno da exclusão social no mundo, que patrocina a fome, a pobreza e a miséria; recentes mudanças políticas, econômicas, sociais e culturais, as quais impactam diretamente em transformações nos modos de vida da população e, consequentemente, em suas relações com a comida e o comer; o crescente interesse pela interface entre alimentação e cultura, seja numa perspectiva antropológica, seja para compreender - na cotidianidade da vida humana - os impasses com que os indivíduos se deparam frente às suas escolhas alimentares.

Além disso, estão sendo ampliadas as políticas públicas sociais em campos como saúde, educação, trabalho e assistência social, em um processo de constituição de ações na direção do enfrentamento às desigualdades sociais (BRASIL, 2014). No Brasil, tal processo permitiu que o país crescesse de forma inclusiva e protagonizasse uma significativa e exigente transição demográfica, epidemiológica e nutricional, caracterizadas com "maior expectativa de vida e redução do número de filhos por mulher, além de mudanças importantes no padrão de saúde e consumo alimentar da população" (BRASIL, 2014, p. 5).

Conforme destacado no novo Guia Alimentar para a População Brasileira (BRASIL, 2014), para o enfrentamento desse cenário, é emergencial o desenvolvimento de uma ação profissional em nutrição que repercuta positivamente sobre os diversos determinantes da saúde e nutrição, atuando na promoção da alimentação adequada e saudável, fundamentando-se em dimensões como o incentivo, apoio e proteção da saúde e combinando iniciativas focadas em políticas públicas saudáveis, na criação de ambientes saudáveis, no desenvolvimento de habilidades pessoais e na reorientação dos serviços de saúde na perspectiva da promoção da saúde, de forma articulada ao desenvolvimento de estratégias para a promoção e a realização do direito humano à alimentação adequada.

Em verdade, experiências produtoras de um agir crítico no âmbito da Nutrição Social têm sido desenvolvidas há muitas décadas, ampliando-se de modo especial desde a década de 1970, especialmente em contextos de exclusão social e no âmbito de comunidades e territórios com ações sanitárias centradas em famílias. Tais experiências caracterizamse, centralmente, por processos de construção compartilhada de ações profissionais e de trabalhos sociais em alimentação e Nutrição, cujo ponto de partida é a realidade social concreta e o diálogo autêntico, respeitoso e propositivo com seus sujeitos e grupos.

Em seu delineamento, essas iniciativas configuram procedimentos e abordagens que valorizam a cultura popular e o fazer interprofissional, indo, portanto, na contramão de um agir conservador em Nutrição, ainda presente na atualidade, o qual é caracterizado por abordagens como recomendações dietéticas e nutricionais realizadas de modo prescritivo e normativo, visando ensinar as pessoas como devem se alimentar "corretamente", tendo como parâmetro apenas a dimensão biológica e desconsiderando tanto os contextos sociais e culturais como também as determinações de saúde com as quais as pessoas convivem. No arcabouço desse agir conservador, as ações educativas em alimentação e Nutrição situamse em modelos tradicionais baseados no tecnicismo, com ênfase na transmissão vertical de informações de alguém "que sabe" para outro alguém "ignorante" (ao menos no que tange ao campo alimentar e nutricional), tendo 
como foco o conhecimento do especialista. Nesse contexto, urge-se, cada vez mais, ampliar e diversificar o leque de produções que se debrucem sobre as práticas em Nutrição Social e desvelem os novos caminhos e conhecimentos que elas têm apontado. É necessário também sistematizar os saberes, fazeres e perspectivas acumulados no seio da práxis dessas iniciativas de trabalhos sociais e profissionais, com vistas a explicitar estratégias educacionais que incentivem o debate em torno das práticas educativas e da ação profissional para a promoção da alimentação e da nutrição com um olhar integral, crítico e reflexivo.

O presente ensaio busca constituir um exercício reflexivo sobre o agir em Nutrição Social e suas interfaces com a Educação Popular $(E P)$, tendo como horizonte, em especial, as práticas profissionais e o trabalho social em alimentação e Nutrição no âmbito da Atenção Primária à Saúde (APS). A intenção é explicitar vivências cotidianas na realidade social como um dos elementos que corroboram com a práxis da aplicação das ações de Educação Alimentar e Nutricional (EAN) e de Segurança Alimentar e Nutricional (SAN) com as comunidades e grupos sociais no contexto da APS. Problematizamos como e por que esse agir pressupõe, em nossa avaliação e dentre suas dimensões, engajamento e compromisso com a realidade social, tendo como referencial tanto a construção de vínculos e diálogos interculturais, como o enfrentamento ao capitalismo.

Cumpre destacar que utilizamos o termo Nutrição Social na perspectiva delimitada por Vasconcelos (2002) em seu estudo "O nutricionista no Brasil: uma análise histórica", dentro do qual ressalta a emergência desse campo científico, ressaltando que aquele pode também ser denominado Nutrição em Saúde Pública, Nutrição em Medicina Preventiva, Nutrição Comunitária ou, ainda, Nutrição em Saúde Coletiva. Tais termos são, em verdade, "produto do processo histórico de especialização e divisão do trabalho/saber no interior da complexa e multidisciplinar ciência da Nutrição, constituída nos anos 1930-1940 no Brasil" (VASCONCELOS, 2002, p. 133).

Este texto construiu-se como produto de tese em Educação, promovida no campo da Nutrição Social à luz da EP, especificamente dentro do Programa de Extensão "Práticas Integrais de Promoção da Saúde e Nutrição na Atenção Básica" (PINAB), do Departamento de Nutrição e do Departamento de Promoção da Saúde da Universidade Federal da Paraíba (UFPB). O Programa PINAB está em exercício há dez anos, entrelaçando ações, grupos e processos educativos direcionados à Promoção da Saúde e à Segurança Alimentar e Nutricional no contexto de comunidades populares, tendo como sujeitos, além de estudantes e docentes da UFPB, moradores, educadores populares, educadores de ensino fundamental e trabalhadores de uma Unidade de Saúde da Família (USF).

Com a realização da pesquisa, explicitou-se categorias que apontam para o agir crítico em Nutrição Social, sendo elas: o engajamento e compromisso com a realidade social; participação, vínculo e construção compartilhada; construção em meio ao conflito e ao enfrentamento do capitalismo; educação em grupos comunitários; a superação do assistencialismo e a reorientação do fazer clássico da Nutrição nas ações de SAN; práxis; e a interdisciplinaridade. Ademais, apontaramse algumas reflexões para a EAN na ótica da EP, dentre elas a percepção da EAN como construção compartilhada, viabilizada pelo diálogo e pela participação popular, que requer mais do que ideias de intelectuais: exige o protagonismo do saber popular.

No presente ensaio, primeiramente, deveremos situar antecedentes significativos para o que chamamos de agir crítico em Nutrição Social e, em seguida, dedicar-nos ao desvelamento da compreensão sobre o 
engajamento e o compromisso com a realidade social como caminho de construção desse agir no campo da APS.

Para a mobilização das reflexões contidas no presente trabalho, tomamos como base o conjunto de uma pesquisa doutoral, dentro da qual recorremos a reflexões oriundas de resultados, aprendizados e conclusões da tese, atendendo aos seguintes critérios: a) relatos e análises críticas de experiências envolvendo a Nutrição Social, a EP e suas interfaces; b) reflexões críticas sobre a ação comunitária e a EP no agir em Nutrição e suas interfaces, comunicações e distanciamentos com as equipes de saúde da família, enfatizando os desafios e também as possibilidades da Nutrição no território no campo da APS.

\section{Breve contextualização histórica sobre o agir crítico em Nutrição Social}

Na década de 1930, Josué de Castro foi o principal responsável pela inserção da Nutrição como questão política e social na agenda pública do país, conferindo-lhe atenção acadêmica singular, consolidando-se com a obra Geografia da Fome em meados da década seguinte. A partir desse e de outros trabalhos de Castro e seus colaboradores, as questões da alimentação e da Nutrição no Brasil vieram a ser paulatinamente compreendidas como fenômenos sociais, políticos, econômicos e culturais.

Esse processo passou a exigir modos de atuação em Nutrição Social distintos dos tradicionais, pois problemas sociais como exclusão, fome, miséria, dentre outros, demandavam um olhar crítico, ampliado e estrutural dos problemas sociais, aliado a abordagens críticas e humanizadas, em uma ação com ênfase social, cultural e educativa (ASSIS et al., 2002; BOOG, 2004; SANTOS, 2005; PÁDUA; BOOG, 2006; CERVATOMANCUSO etal., 2012; VASCONCELOS, 2013).
Diversas práticas no campo social passaram a ser implementadas em contato com as questões alimentares e nutricionais, principalmente a partir da década de 1970, quando a construção de saberes e o engendramento de movimentos na direção de um agir nutricional integrado com a dinâmica da vida e da realidade social foram oportunizados. Primeiramente, isso ocorreu por iniciativas de agentes sociais comunitários e profissionais de saúde (não necessariamente nutricionistas) no interior de práticas de saúde comunitária, nas quais a fome, a miséria e a desnutrição eram problemas centrais no sentido da promoção da saúde.

Nessas ações, destacaram-se estratégias alternativas de complementação alimentar, ou mesmo mobilização comunitária (como hortas), e também trabalhos educacionais para sensibilização e orientação da população, como rádios comunitárias, grupos de educação em saúde, visitas domiciliares, fortalecimento de redes de apoio social nas comunidades e valorização de movimentos reivindicativos.

Foram experiências como a do Movimento Popular de Saúde (MOPS) em vários recantos do país, da Pastoral da Criança, da Pastoral da Saúde e da Pastoral da Terra, além de atividades de movimentos sociais ligados à luta pela terra, como o Movimento dos Trabalhadores Rurais Sem Terra (MST), que, na época, estava começando. Essas ações aconteciam em contextos de precariedade estrutural e de poucos recursos financeiros, mas prosperavam graças à disposição de agentes sociais e profissionais de saúde para uma atuação conjunta, em que se vislumbrava, efetivamente, o diálogo entre saberes científico e popular como estratégia para superar os problemas nutricionais e alimentares.

$\mathrm{Na}$ perspectiva da EP, fundamentada por Paulo Freire, havia um referencial para abordar os problemas e construir práticas sociais de forma compartilhada. Nesse contexto, a EP agregava também a dimensão da intencionalidade dessas ações, pois, sendo promovidas no período 
da ditadura militar, em cada passo dado, era eminentemente necessário saber qual era o projeto almejado de sociedade, ou seja, qual horizonte social e político era vislumbrado como objetivo de conquista com aquelas ações.

Essas experiências foram empreendidas em meio a fatores como a luta contra a ditadura militar e a exploração econômica nos anos 1970. As ações de EAN decorriam em meio à busca por uma sociedade mais justa e solidária, em um processo de resistência e reconstrução política e social como resposta à opressão e repressão política. A luta era ampla: por um sistema de saúde justo, participativo e universal. Mais que isso, por uma sociedade solidária, com direito à diversidade e à democracia. Nesse período, a fome e a desnutrição no Brasil eram fenômenos sociais com repercussões humanitárias assustadoras. Tal processo mobilizou a atenção e a ação de todos os agentes sociais, populares e profissionais envolvidos nas ações de cuidado e atenção à saúde. Dessa maneira, os problemas alimentares e nutricionais desvelavam-se não apenas como uma preocupação própria de nutricionistas, mas como um fenômeno cujo enfrentamento necessitava da ação multiprofissional e interdisciplinar. Nesse sentido, essas experiências e iniciativas pioneiras não se deram apenas no núcleo profissional da Nutrição, mas se desenvolveram a partir da integração multiprofissional e social, tendo na interdisciplinaridade e na construção coletiva, princípios e valores que foram fundantes.

Esse processo ocorreu ainda no contexto do Movimento de Reforma Sanitária, no qual a ação multiprofissional em diálogo com os movimentos populares estimulava a organização de iniciativas de promoção da saúde na perspectiva do direito à saúde, da participação da comunidade, do cuidado integral e da universalidade do acesso. Dessa forma, as práticas sociais em alimentação e Nutrição estavam também no bojo de diversificadas experiências que foram singulares na construção e criação do Sistema Único de Saúde (SUS).

A partir desse quadro, o potencial das práticas sociais no campo alimentar e nutricional ensejou caminhos e possibilidades para o fortalecimento do debate em torno da Nutrição como prática social transformadora em meados dos anos 1980. Nessa mesma década, muitas ações de combate à fome e à desnutrição foram empreendidas, inclusive por programas e ações anteriores à criação do SUS em 1988. Essas ações fizeram-se importantes, pois, posteriormente, foram incorporadas pelo SUS.

No processo de construção do SUS, por meio de movimentos como o MOPS e o Movimento pela Reforma Sanitária, os diversos debates em torno do direito à saúde e da participação comunitária revelaram que o profissional que atuava com alimentação e Nutrição não apenas tinha contribuições significativas a empenhar em seu núcleo profissional, mas precisava participar dos trabalhos sociais direcionados à construção de políticas e ações de promoção, prevenção e cuidado em saúde que rumassem no sentido da integralidade, do acesso universal e da equidade.

Na década de 1990, com o fortalecimento do SUS, por meio da criação e expansão do Programa Saúde da Família (atualmente compreendidocomoEstratégiaSaúdedaFamília), as políticas públicas de Nutrição passaram a ser ampliadas e a incorporarem novas perspectivas. Em muitas experiências espalhadas pelo país, o nutricionista passou a estreitar os laços de sua atuação com os empreendimentos e iniciativas sociais de combate à fome, à desnutrição e à pobreza (FERREIRA; MAGALHÃES, 2007; VASCONCELOS, PEREIRA; CRUZ, 2008). Assim, constitui-se no cotidiano do setor saúde um fazer profissional em nutrição diferenciado daquele cuja ênfase está apenas nas dimensões biológicas e fisiológicas, retratando uma visão tecnicista da dietética e da dietoterapia. Em meio a esse contexto, no período 
pós-ditadura, novas perspectivas teóricas e conceituais que orientavam novas políticas e ações para a Nutrição passaram a ser delineadas por intelectuais e pesquisadores. Expoentes como Flávio Valente, Maria Cristina Faber Boog, dentre outros, passaram a provocar debates e reflexões importantes acerca das possibilidades e dos desafios para uma EAN que fosse crítica, ou seja, imbuída de aspectos fundamentais como o compromisso, a participação, a dialogicidade, dentre outros.

Confirmando esses avanços no campo acadêmico, no âmbito social, a questão da fome e da miséria passou a demandar crescente atenção popular, o que se fortaleceu por meio de diversos movimentos, mobilizações e ações em defesa da vida, com destaque para a que foi liderada pelo sociólogo Betinho. Nesse cenário, particularmente na década de 1990, os conceitos de SAN e de Direito Humano à Alimentação Adequada e Saudável (DHAAS) foram fortalecidos, os quais representam a expressão nítida da ênfase defendida para as práticas sociais em Nutrição: a alimentação como direito, de forma sustentável, com boa qualidade e quantidade suficiente, respeitando-se hábitos, costumes e todos os aspectos relativos à cultura das pessoas e dos grupos sociais. Isso foi vivenciado com maior regularidade a partir do Governo Lula em 2003, em que, dentre outras medidas, a criação do Ministério de Desenvolvimento Social e Combate à Fome (MDS) e do Programa Fome Zero demarcaram uma decisão assertiva do Governo Federal no sentido de inaugurar novas abordagens para a implementação de políticas públicas nesta área. Dentre elas, o conceito de SAN se sobressai (VASCONCELOS; PEREIRA; CRUZ, 2008; BURITY et al., 2010).

Certamente, o conceito de SAN não nasce nos anos 1990, e tampouco é exclusividade do Governo Lula. Como dito anteriormente, desde os anos 1970, diversos profissionais de saúde e militantes sociais já vinham empreendendo saberes e práticas sociais compromissadas com o enfrentamento dos problemas nutricionais de modo emancipatório e humanizado. Contudo, no período histórico da década de 1990, e depois na gestão federal iniciada em 2003, o conceito de SAN foi, paulatinamente, representando um diferencial, pois sintetizou, de forma sucinta e objetiva, tanto um conjunto de princípios, como uma série de elementos práticos, e ainda a imagem-objetivo de onde se queria chegar, com uma abordagem crítica das questões alimentares e nutricionais. De acordo com Vasconcelos (2013), foram marcos históricos nesse contexto: o ressurgimento do Conselho Nacional de Segurança Alimentar (CONSEA), a formulação e operacionalização do Programa Fome Zero, a instituição do MDS, e as consequentes realizações da II e III Conferência Nacional de Segurança Alimentar e Nutricional (CNSAN). A Lei Orgânica de Segurança Alimentar e Nutricional - LOSAN (BRASIL, 2006) constituiu outro marco fundamental nesse percurso histórico, à medida que sistematizava e fundamentava uma definição de SAN que ilustrou decisivamente o quão significativa foi para o amplo histórico de movimentos e práticas sociais de Nutrição numa perspectiva crítica.

Esse cenário passa a provocar uma notável transformação na abordagem governamental sobre alimentação e Nutrição, bem como algumas mudanças na atuação profissional e na formação em Nutrição, seja em seus princípios éticos, nos aspectos políticos ou nas questões quanto às formas de atuar e participar, especialmente em contextos permeados pela exclusão social (AMORIM; MOREIRA; CARRARO, 2001; MOTTA; OLIVEIRA; BOOG, 2003; BOOG, 2008; RECINE et al., 2012). Nessa direção, em 2012, a atualização da Política Nacional de Alimentação e Nutrição (BRASIL, 2012a) traz questões relevantes, voltadas para a reorientação da prática profissional e, principalmente, para a formação na linha 
da SAN e do DHAAS. Em 2012, a criação do Marco de Referência de Educação Alimentar e Nutricional nas Políticas Públicas (BRASIL, 2012b) constituiu um avanço significativo na delimitação de caminhos para uma educação crítica no contexto das ações de SAN e DHAAS.

Quantoà atuação em Nutrição no contexto da APS, por meio de vários projetos e programas, passou-se a demandar um aprimoramento de seu protagonismo na construção de ações educativas, de mobilizações sociais e de estratégias de ação política, perfazendo uma série de caminhos capazes de promover a saúde com ênfase em estratégias e políticas coerentes com suas realidades e problemáticas regionais relacionados à fome e à miséria, envolvendo a SAN como mais um referencial singular no processo de desenvolvimento social e de combate à fome (BOOG, 2004; SANTOS, 2005).

\section{Alguns caminhos possiveis para a construção do agir crítico em nutrição social}

De acordo com o que explicitamos inicialmente, a pesquisa da qual nasceram essas reflexões identificou uma série de elementos constituintes do agir crítico em Nutrição Social à luz da EP. Tendo em vista a construção desse ensaio e a objetividade necessária a um artigo científico, abordaremos apenas um desses elementos, podendo os demais serem consultados pelo leitor diretamente na tese doutoral (CRUZ, 2015a) ou em futuros artigos. Dessa maneira, pautaremos aqui as vivências cotidianas na realidade social, sobretudo por meio do engajamento e o compromisso, como pressuposto do agir crítico em nutrição.

O compromisso, próprio da existência humana, só existe no engajamento com a realidade, de cujas "águas" os homens verdadeiramente comprometidos ficam "molhados", ensopados. (FREIRE, 1996, p. 19).
Todo agir em Nutrição é, evidentemente, envolto pela realidade social, seja no hospital, na clínica, no mundo esportivo, nas unidades de produção de refeições, nas indústrias e laboratórios, instituições acadêmicas, dentre outros cenários, inclusive porque as práticas alimentares constituem "uma expressão sociocultural de significados que (re)produz códigos de identificação para as pessoas em seu contexto social. Comer é uma experiência social" (BARBOSA et al., 2013, p. 941).

No entanto, em nossa compreensão, nem todo agir em Nutrição se deixa encharcar pela realidade social circundante, na acepção trazida por Freire na citação anterior. Do deixarse encharcar pela realidade social emerge um engajamento, cristalinamente demonstrado por compromisso social.

É preciso, pois, deixar que o nutricionista ou qualquer outro profissional, no campo daSAN, engaje-se nas "águas" da realidade local, ao invés de chegar já determinando o que será feito, quais grupos serão empreendidos ou escolher apenas ações clássicas da Nutrição: grupo de obesos, diabéticos e hipertensos, ou prescrever dietas.

O profissional que vai trabalhar com Nutrição ou com a SAN não pode ficar restrito às paredes do seu serviço. Seja na USF, na assistência social, na cozinha comunitária, seja onde for. O agir crítico em Nutrição Social não fica dentro de quatro paredes de serviços, mas procura os grupos sociais comunitários ou, pelo menos, se mantém aberto para que eles apareçam.

É a partir dessa atitude que começaremos a perceber oquanto ossabereseas experiências das pessoas e grupos da comunidade agregam para a construção de práticas sociais com consequência e contribuição efetiva à realidade social.

Nessa direção, a construção desse agir requer dos sujeitos das práticas sociais e profissionais a compreensão de que o fenômeno da Nutrição está intimamente ligado à alimentação como ação cultural, e que tanto alimentação como nutrição constituem 
elementos da vida cotidiana das pessoas que estão sujeitas às mudanças próprias da realidade social, aos jogos de interesses nas relações humanas, às questões econômicas e políticas da vida em comunidade, dentre outros fatores.

Muitas vezes, a ação profissional em Nutrição procura ignorar e se afastar dos espaços e movimentos de conflitos sociais, políticos, econômicos e culturais, posto que lidar com tais situações não é ensinado no currículo básico do curso de Nutrição na maioria das universidades, o qual, em verdade, enfatiza apenas a apreensão de normas, procedimentos e aparatos técnicos para que se possa agir de maneira científica e tecnicamente adequada sobre as doenças e agravos em geral. Tal concepção deriva da visão da saúde como ausência da doença e do profissional como o "mecânico" que "conserta" as pessoas (CRUZ, 2015b).

Todavia, na perspectiva de um agir crítico orientado por vivências com a realidade, um elemento fundador revela-se na convivência com os seus protagonistas, por meio da qual se desvela um processo rico, exigente e complexo de diálogo intercultural e de tessitura de vínculos intersubjetivos, nos quais as relações profissionais-usuários transbordam essa dimensão para se pautaram pela ideia e pelo sentimento de relações entre humanos. Desse ponto em diante, o agir em Nutrição Social pode incluir um processo rico e dinâmico de se orientar pelo estabelecimento de encontros significativos e de espaços de aprendizagens entre pessoas, as quais - mesmo com papeis diferentes empenham-se em um objetivo comum, qual seja a promoção integral e plena da saúde.

Por essa perspectiva, as vivências cotidianas na realidade incluem, essencialmente, a abertura do profissional de saúde para uma relação humana porosa às intersubjetividades, por meio da qual se dá, mesmo que sutilmente, um encontro entre os sentidos de quem vive no território comunitário e de quem vive a aplicação da ciência da Nutrição.
Na vivência profissional, essa dimensão pode ser praticada por meio de um agir permeado pelo diálogo na acepção freiriana e pela convivência cotidiana com os grupos sociais comunitários, os setores territorializados diversos e seus protagonistas. Grupos e momentos de encontro em trabalhos sociais que ensejem, fundamentalmente, não apenas "ver" a realidade do território e suas peculiaridades, mas o encontro com as pessoas em seus próprios espaços e cenários, mesmo em contextos de vulnerabilidade e insegurança.

Além disso, o vínculo contribui para estabelecer um ambiente propício para o compartilhamento e problematização de questões sutis provindas de dilemas e anseios da população. Em um encontro humano permeado pelo vínculo, conflui-se para o estabelecimento de conversas francas, no qual limites como o tráfico de drogas, a violência, a fome, a miséria e a baixa renda, dentre outros, possam ser postos de forma aberta e transparente. Um vínculo que favoreça um diálogo autêntico em que a ciência da Nutrição, o saber popular e as experiências da vida teçam estratégias de luta e enfrentamento para atitudes criadoras de inéditos-viáveis em contextos de pobreza e exclusão. Mas não basta cultivar esse vínculo entre sujeitos para construir um agir com base nas vivências cotidianas. Para existir, o agir crítico em Nutrição Social na APS pressupõe uma gestão participativa de suas ações. Todas as pessoas que fazem parte dos trabalhos têm que se apropriar das dimensões políticas e dos direcionamentos de cada atuação.

No campo das práticas de EAN, isso pressupõe também compartilhar com as pessoas da comunidade o poder de decisão sobre os temas a serem discutidos nos espaços de encontro e atividades educativas. Para além disso, tal dimensão recomenda ao nutricionista uma abordagem que não fique centrada somente em conteúdos ou roteiros temáticos pré-estabelecidos. 
O agir crítico exige ainda uma abordagem participativa de tais temas, de modo que seja valorizado o saber de experiência de cada sujeito inserido nas atividades, que devem ter como ponto de partida o concreto vivido em suas realidades, na dinâmica dos grupos sociais locais. Nesse sentido, há necessidade de se construírem as pautas das ações educacionais junto com a população envolvida, de modo que as pessoas não sejam tão somente espectadoras no momento educacional, mas também corresponsáveis pela condução do grupo e das temáticas debatidas.

Construir de forma compartilhada implica também gerir coletivamente os aspectos organizacionais e administrativos da experiência. Por exemplo, se o nutricionista for fazer qualquer trabalho em algum território de uma comunidade, é importante que esse processo envolva as pessoas daquele lugar e que elas sejam também protagonistas, reconhecendo-as como "sujeitos". E, para isso, elas têm que participar de tudo, inclusive da gestão desse processo. Na EP, o agir crítico em Nutrição Social precisa do envolvimento de todas as pessoas que participam da ação, com um movimento ativo e "protagônico". Nesse sentido, o papel desse agir é também promover a autogestão dos processos sociais e educativos empreendidos no território. Todo processo desenvolvido tem que estar preocupado com a sustentabilidade, independentemente de quais pessoas estão envolvidas.

Para tanto, um elemento fundante é, necessariamente, o reconhecimento autêntico da capacidade de "ser mais" de cada indivíduo na comunidade. É essencial a confiança em dispor a esses sujeitos e seus grupos sociais o íntimo de cada atividade educativa, de modo que possam opinar, interferir, participar.

Esses caminhos são exigentes, sobretudo porque se deve desconsiderar que a produção de conhecimentos e saberes em torno da alimentação e nutrição não pode fugir dos determinantes sociais de saúde e suas interfaces. Conforme ressalta Valente (1986), a reflexão social sobre a fome/desnutrição passa pela análise do modo de produção capitalista. Conforme o autor, a EAN deveria visar à superação das "causas básicas" da problemática nutricional, representadas pela estrutura econômica, política e ideológica dos locais onde o nutricionista atua; disso se depreende que a EAN se configura como um instrumento de apoio às ações sociais que visam explicitar as contradições da estrutura social, em um esforço para a superação das causas básicas dos problemas nutricionais das populações (LINS, 1990; LIMA; OLIVEIRA; GOMES, 2003).

Conforme aponta Vasconcelos (2015), muitos profissionais de saúde ignoram a dimensão das formas de organização social, política e econômica na vida comunitária, por julgarem-nas incapazes de intervir nesse cenário, dada a sua conformação macroestrutural. No entanto, observa-se que é justamente na ação circunscrita a determinadas comunidades e grupos sociais, com recursos muitas vezes limitados, que muito se pode fazer para o enfrentamento dos conflitos e contradições do capitalismo. Pois, se é verdade que sozinhos os profissionais não mudarão o sistema, em nível comunitário, diversas intervenções, ações, dinâmicas, posturas e apoios sociais podem ajudar a enfrentar problemas como a desnutrição, mesmo que socialmente determinado por muitos e complexos fatores. A abordagem coletiva e educativa pode resultar na melhoria concreta da qualidade de vida das pessoas, apropriando-as dos determinantes sociais de sua saúde de modo a enfrentarem e buscarem superar o que oprime e incomoda.

O agir crítico em Nutrição Social pressupõe a pró-atividade diante do caráter excludente da organização social atual. Tal constatação carrega consigo, como implicação, a organização das pessoas em torno de grupos. As saídas para a atual encruzilhada do sistema capitalista não 
ocorrerão por uma ação individual de quem quer que seja, mas somente pela colaboração em ação coletiva das pessoas e grupos sociais, em torno de novas perspectivas, atitudes, projetos e formas de atuar e se organizar na sociedade - distantes da perspectiva exploratória e desumanizante do capitalismo.

Em nossa compreensão, pensar o agir crítico em Nutrição Social pressupõe a inquietação epistemológica permanente com o desafio de construir um agir em Nutrição na APS coerente com os atuais avanços teóricos e políticos da Nutrição Social, da SAN e da EAN, conforme anteriormente situados.

Nesses termos, tal agir perpassa uma abordagem da ciência da Nutrição que compreende a si mesma como multifacetada, com elementos como o social, o econômico, o político, o cultural, o espiritual, o mental, dentre outros. Uma ciência cujo ponto de partida é a realidade, suas contradições e seu movimento, compreendendo o fenômeno nutricional com sua natureza biológica e fisiológica, mas centralmente indissociado de um entendimento ampliado da alimentação, como uma prática plena de sentidos nas vidas das pessoas e das coletividades. Tal agir envolve, em sua prática, dimensões como a participação, a construção compartilhada do conhecimento, a amorosidade e a criatividade. Apontam para este agir eixos como: a inserção profunda na realidade social; a participação, a autonomia, a construção compartilhada do conhecimento e a criação de vínculos; a construção em meio ao conflito; a educação em grupos comunitários; a superação do caráter assistencialista dos programas de SAN; e o desvelamento de novos caminhos para dimensões tradicionais do agir em Nutrição.

Essencialmente, um ato que contribua para uma "aplicação edificante da ciência" (SANTOS, 1989) da Nutrição, a qual seja capaz de "instigar a reflexão conjunta que se entrelace nas práticas sociais, interagindo, e acrescentando algo significativo ao cotidiano da vida das pessoas" (SCHNEIDER; NEVES, 2014, p. 189). Na acepção de Boaventura de Sousa Santos (1989), uma aplicação edificante se desenvolve em situação concreta, considerando a existência, os interesses e as buscas de todas as pessoas que interagem naquele contexto. Em sua visão, essa aplicação é um processo de diálogo e de argumentação, na qual o cientista precisa lutar pelo equilíbrio de poder, tomando partido dos que possuem menos poder. Tal aplicação tenta ainda reforçar as definições emergentes e alternativas da sociedade. Para essa aplicação, os limites e deficiências dos saberes locais não justificam sua recusa, alienação ou exclusão, tampouco a recusa de suas possibilidades de também enunciarem saberes e conhecimentos (SANTOS, 1989).

A Nutrição Social e suas ações profissionais precisam estar integradas com a vida. Por exemplo, refletindo atitudes inconformistas perante a exclusão social, engendrando esforços de enfrentamento diante das determinações sociais e econômicas do contexto atual, de maneira articulada com os contextos culturais (SILVA et al., 2010) vivenciados pelas pessoas. Para tanto, é fundamental desvelar abordagens para a Nutrição que sejam coerentes com uma ação científica cujo compromisso seja, conforme dito por Castro, Castro e Gugelmim (2011, p. 18), o "reposicionamento da alimentação como uma prática plena de sentido no âmbito da vida cotidiana".

\section{Considerações finais}

Com esse artigo esperamos ter mantido aceso o debate sobre os esforços que muitos autores já vêm mantendo em relação à EAN. Apresentamos, por outro lado, a possibilidade de haver uma interlocução da EP com a Nutrição Social, efetivando práticas transformadoras dos processos educativos em alimentação e nutrição. 
Avaliamos ser necessário priorizar, não só no curso de Nutrição, mas em qualquer curso de graduação em saúde, o desenvolvimento de um agir crítico, expresso por meio de uma prática educativa em Alimentação e Nutrição emancipatória. Uma prática que revele as dimensões multifacetadas da Nutrição e as possibilidades de se vislumbrar, mesmo que em exercícios e lances, uma EAN permeada de categorias como: diálogo, criticidade, participação, amorosidade e compromisso social popular.

O agir em Nutrição constrói possibilidades diversas de "ser mais" e de viver melhor em práticas sociais e profissionais possibilitadoras do exercício do diálogo acerca das estratégias para posicionar a alimentação e a Nutrição a serviço de uma vida melhor, sem abrir mão, em momento algum, de atitudes, posturas e princípios éticos de uma convivência social respeitosa. Como prática social, a Nutrição pode desvelar um processo de investigação que não construa verdades absolutas, mas que desvele uma multiplicidade de verdades, para que possamos compreender bem mais a realidade alimentar e nutricional do país e do mundo.

Nessa perspectiva, no campo social, as práticas em Nutrição requerem ações que alimentem o ato de conhecer, indagando e compreendendo o mundo cada vez mais e melhor, para gerar mais dimensões, compreensões e conhecimentos sobre a vida, em um processo de comunicação e de diálogo permanente entre as pessoas e os grupos sociais. Em nossa visão, a EP é um referencial teórico, metodológico, ético e político fundamental que reorienta a Nutrição como prática social e profissional. Possui princípios, intencionalidades e abordagens capazes de trazer elementos para a superação da distância entre o debate crítico em torno da Nutrição e suas realizações no campo prático, particularmente as educacionais.

\section{Referências}

AMORIM, S. T. S.; MOREIRA, H.; CARRARO, T. E. A formação de pediatras e nutricionistas: a dimensão humana. Rev Nutr, Campinas, v. 14, n. 2, p. 111-118, ago. 2001. Doi: 10.1590/S141552732001000200004.

ASSIS, A. M. O. et al. O Programa Saúde da Família: contribuições para uma reflexão sobre a inserção do nutricionista na equipe multidisciplinar. Rev Nutr, Campinas, v. 15, n. 3, p. 255-266, set. 2002. Doi: 10.1590/S1415-52732002000300001.

BARBOSA, N. V. S. et al. Alimentação na escola e autonomia: desafios e possibilidades. Ciênc. Saúde Coletiva, Rio de Janeiro, v. 18, n. 4, p. 937-945, 2013. Doi: 10.1590/S1413-81232013000400005.

BRASIL. Ministério da Saúde. Secretaria de Atenção à Saúde. Departamento de Atenção Básica. Guia alimentar para a população brasileira. 2. ed. Brasília: Ministério da Saúde, 2014.

BRASIL. Ministério da Saúde. Secretaria de Atenção à Saúde. Departamento de Atenção Básica. Política nacional de alimentação e nutrição. Brasília: Ministério da Saúde, 2012a.

BRASIL. Ministério do Desenvolvimento Social e Combate à Fome. Marco de referência de educação alimentar e nutricional para as políticas públicas. Brasília: MDS, 2012b.

BRASIL. Presidência da República. Lei no 11.346, de 15 de setembro de 2006. Cria o Sistema Nacional de Segurança Alimentar e Nutricional - SISAN com vistas em assegurar o direito humano à 
alimentação adequada e dá outras providências. Diário Oficial da União. 18 set. 2006. Disponível em: http:/www.planalto.gov.br/ccivil_03/_ato2004-2006/2006/lei/l11346.htm. Acesso em: 10 nov. 2018.

BOOG, M. C. F. Atuação do nutricionista em saúde pública na promoção da alimentação saudável. Revista Ciência \& Saúde, Porto Alegre, v. 1, n. 1, p. 33-42, jan./jun. 2008. Doi: 10.15448/1983652X.2008.1.3860.

BOOG, M. C. F. Contribuições da educação nutricional à construção da segurança alimentar. Saúde em Revista, Piracicaba, v. 6, n. 13, p. 17-23, 2004.

BURITY, V. et al. Direito humano à alimentação adequada no contexto da segurança alimentar e nutricional. Brasília: ABRANDH, 2010.

CASTRO, I .R. R.; CASTRO, L. M. C.; GUGELMIM, S. A. Ações educativas, programas e políticas envolvidas nas mudanças alimentares. In: DIEZ-GARCIA, R. W.; CERVATO-MANCUSO, A. M. (coord.). Mudanças alimentares e educação nutricional. Rio de Janeiro: Guanabara Koogan, 2011. p. 18-34.

CERVATO-MANCUSO, A. M. et al. atuação do nutricionista na Atenção Básica à Saúde em um grande centro urbano. Ciênc. Saúde Coletiva, Rio de Janeiro, v. 17, n. 12, p. 3.289-3.300, dez. 2012. Doi: 10.1590/S1413-81232012001200014.

CRUZ, P. J. S. C. Agir crítico em nutrição: uma construção pela educação popular. 2015. 397 f. Tese (Doutorado em Educação) - Centro de Educação, Universidade Federal da Paraíba, João Pessoa, 2015a.

CRUZ, P. J. S. C. De mecânico de gente a companheiro na luta pela vida. In: VASCONCELOS, E. M.; FROTA, L. H.; SIMON, E. (org.). Perplexidade na universidade: vivências nos cursos de saúde. 2. ed. São Paulo: Hucitec, 2015b. p. 179-181.

FERREIRA, V. A.; MAGALHÃES, R. Nutrição e promoção da saúde: perspectivas atuais. Cad. Saúde Pública, Rio de Janeiro, v. 23, n. 7, p. 1674-1681, jul. 2007. Doi: 10.1590/S0102$311 \times 2007000700019$.

FREIRE, P. Pedagogia da autonomia: saberes necessários à prática educativa. São Paulo: Paz e Terra, 1996. $144 \mathrm{p}$.

LIMA, E. S.; OLIVEIRA, C. S.; GOMES, M. C. R. Educação nutricional: da ignorância alimentar à representação social na pós-graduação do Rio de Janeiro (1980-1998). Hist. cienc. saudeManguinhos, Rio de Janeiro, v. 10, n. 2, p. 602-635, ago. 2003. Doi: 10.1590/S010459702003000200006.

LINS, M. E. P. Educadores nutricionais: que somos e a que viemos? Contribuições para repensar a disciplina educação nutricional como elemento formador e objeto de trabalho do nutricionista. 1990. Dissertação (Mestrado em Nutrição) - Instituto de Nutrição, Universidade Federal do Rio de Janeiro, Rio de Janeiro, 1990.

MOTTA, D. G.; OlIVEIRA, M. R. M.; BOOG, M. C. F. A formação universitária em Nutrição. Pro- 
Posições, Campinas, v. 14, n. 1, p. 69-86, jan./abr. 2003.

PÁDUA, J. G.; BOOG, M. C. F. Avaliação da inserção do nutricionista na Rede Básica de Saúde dos municípios da Região Metropolitana de Campinas. Rev Nutr, Campinas, v. 19, n. 4, p. 413-424, ago. 2006. Doi: 10.1590/S1415-5273200600040000.

RECINE, E. et al. A formação em saúde pública nos cursos de graduação de Nutrição no Brasil. Rev Nutr, Campinas, v. 25, n. 1, p. 21-33, fev. 2012. Doi: 10.1590/S1415-52732012000100003.

SANTOS, B. S. Introdução a uma ciência pós-moderna. Rio de Janeiro: Graal, 1989. 176 p.

SANTOS, L. A. S. Educação alimentar e nutricional no contexto da promoção de práticas alimentares saudáveis. Rev Nutr, Campinas, v. 18, n. 5, p. 681-692, set./out. 2005. Doi: 10.1590/S141552732005000500011.

SANTOS, L. A. S. O fazer educação alimentar e nutricional: algumas contribuições para reflexão. Ciênc. saúde coletiva, Rio de Janeiro, v. 17, n. 2, p. 455-462, fev. 2012. Doi: http://dx.doi. org/10.1590/S1413-81232012000200018.

SCHNEIDER, O. M. F.; NEVES, A. S. Conversas sobre formarfazer a nutrição: as vivências e percursos da Liga de Segurança Alimentar e Nutricional. Interface, Botucatu, v. 18, n. 48, p. 187-196, 2014. Doi: 10.1590/1807-57622012.3846.

SILVA, J. K. et al. Alimentação e cultura como campo científico no Brasil. Physis, Rio de Janeiro, v. 20, n. 2, p. 413-442, 2010. Doi: 10.1590/S0103-73312010000200005.

VALENTE, F. L. Fome e desnutrição: determinantes sociais. São Paulo: Cortez, 1986.

VASCONCELOS, A. C. C. P. Práticas educativas em segurança alimentar e nutricional: a experiência da estratégia saúde da família em João Pessoa-PB. 2013. 281 f. Tese (Doutorado em Saúde Pública) - Escola Nacional de Saúde Pública Sergio Arouca, Fundação Oswaldo Cruz, Rio de Janeiro, 2013.

VASCONCELOS, A. C. C. P.; PEREIRA, I. D. F.; CRUZ, P. J. S. C. Práticas educativas em nutrição na atenção básica em saúde: reflexões a partir de uma experiência de extensão popular em João Pessoa-Paraíba. Rev APS, Juiz de Fora, v. 11, n. 3, p. 334-340, 2008.

VASCONCELOS, E. M. Educação popular e atenção à saúde da família. 6. ed. São Paulo: Hucitec, 2015. $332 \mathrm{p}$.

VASCONCELOS, F. A. G. O nutricionista no Brasil: uma análise histórica. Rev Nutr, Campinas, v. 15, n. 2, p. 127-138, mai./ago. 2002. Doi: /10.1590/S1415-52732002000200001.

Submetido em 12 de novembro de 2018.

Aprovado em 2 de dezembro de 2018. 